\title{
Smartphone induced eye strain in young and healthy individuals
}

\section{Nayak R', Sharma K A², Mishra K S3, Bhattrai $S^{4}$, Sah K N5 , Sanyam D S 6 iD}

${ }^{1}$ Rakhi Nayak, Optometrist, Department of Ophthalmology, Maharajgunj Medical Campus, Institute of Medicine, Kathmandu, ${ }^{2}$ Ananda Kumar Sharma, Professor, Department of Ophthalmology, Maharajgunj Medical Campus, Institute of Medicine, Kathmandu, Nepal, ${ }^{3}$ Sanjeeb Kumar Mishra, Lecturer, Department of Ophthalmology, Maharajgunj Medical Campus, Institute of Medicine, Kathmandu, Nepal, ${ }^{4}$ Sanjeev Bhattrai, Lecturer, Department of Ophthalmology, Maharajgunj Medical Campus, Institute of Medicine, Kathmandu, Nepal, ${ }^{5}$ Nirajan Kumar Sah, Senior optometrist, Sagarmatha Choudhary Eye Hospital, Lahan, Nepal, ${ }^{6}$ Sandip Das Sanyam, Clinical research coordinator, Sagarmatha Choudhary Eye Hospital, Lahan, Nepal.

\begin{abstract}
Background: Usage of digital devices has become one's basic need. Digital eye strain is repeatedly noticed sequelae in optometry practice.

Objectives: This study aims to estimate the different aspects of eye strain.

Methodology: Altogether, 55 students with a mean age of 21.25 years, vision ( $\geq 6 / 9)$ were enrolled. A survey related to common asthenopic (eyestrain) symptoms was carried before and after reading an extract from a novel. Accommodative facility and non-invasive first tear breakup (NTBUT) time were measured before and after the reading. The viewing distance to a smartphone was measured every 20 min.

Results: The total eye strain symptom score was significantly greater post-experiment (score $=7.07 \pm 2.84$ ) than preexperiment (score $=1.54 \pm 1.60, p<0.001$ ). Symptoms of tired eyes, sore eyes, and sleepy eyes increased significantly after $60 \mathrm{~min}$ of a smartphone use $(\mathrm{p}<0.05)$. The mean viewing distance while using a smartphone over 60 min was $30.15 \pm$ $3.29 \mathrm{~cm}$. There was a significant correlation between change in total symptom score and change in viewing distance $(r$ $=-0.301, p=0.026)$. The symptom that correlated with a change in viewing distance was 'sore eyes' $(r=-0.382, p=0.04)$ and sleepy eyes $(r=-0.363, p=0.06)$. There was a significant decrease in monocular and binocular accommodative facilities and NTBUT after 60 min of reading.

Conclusion: Closer viewing distance and eyestrain symptoms are obvious after a smartphone reading. Prolonged use of smartphones appears to have important implications for accommodative function, causing ocular symptoms having an impact on quality of life.
\end{abstract}

Key words: Accommodation, asthenopia, dry eye, eyestrain, smartphone.

Access this article online

Website: www.jkmc.com.np

DOI: https://doi.org/10.3126/jkmc.v9i4.38092

\section{HOW TO CITE}

Nayak R, Sharma K A, Mishra K S, Bhattrai S, Sah K N, Sanyam D S. Smartphone induced eye strain in young and healthy individuals. J Kathmandu Med Coll. 2020;9(4):201-6.

Address for correspondence

Sanyam Das Sandip

Clinical research coordinator, Department of Cornea Research, Sagarmatha Choudhary Eye Hospital, Lahan-3, Siraha, Nepal

E-mail: dassandiip@gmail.com

Copyright $\odot 2020$ Journal of Kathmandu Medical College (JKMC) ISSN: 2019-1785 (Print), 2091-1793 (Online)

(i) (8) This work is licensed under a Creative Commons Attribution-Non Commercial 4.0 International License.

\section{INTRODUCTION}

sthenopia (eye strain) is a condition which manifests Aas nonspecific symptoms like discomfort, fatigue, blurred vision, headache, occasional double vision, and sore eyes with pain in or around. Smartphone/cell phone, a common example of VDT (Visual Display Terminal), is used widely in the general population'. Smartphones have become part of day to day life in the majority of the population, including medical students just because it is handy, portable, and can accommodate multiple tasks at one place ${ }^{2}$.

Studies from around the world revealed some jawdropping facts on a smartphone user. By 2020, smartphone users will reach 2.87 billion worldwide ${ }^{3}$. The Nepal Telecommunication Authority predicted 
38.3 million mobile phone users by the year 2019. $85 \%$ of students personally own a smartphone in Canada ${ }^{4}$. It is $80 \%$ in the U.K. and U.S . $100 \%$ in South Korea and Saudi Arabian university students 6 . India revealed 96\% of students having a smartphone ${ }^{2}$. cross-sectional study of a smartphone addiction among medical students in Nepal showed $36.8 \%$.

Reading a text versus using a phone, the smartphone is viewed at a closer distance where prolonged usage increases the accommodative and vergence demand, which might exacerbate symptoms of digital eye strain. The reason to conduct this study was to quantify the accommodative demand and eye strain in broadened utilization of cell phones. This investigation likewise intends to teach students for sound computerized gadget utilization and adhere to the standard of 20:20:20 (every 20 minutes of work look 20 feet away for 20 seconds) ${ }^{8}$.

\section{METHODOLOGY}

A hospital-based, descriptive, cross-sectional, and experimental study was carried out at Institute of Medicine (IOM), Nepal. The study was conducted with the permission from the Institutional Review Board for a duration of one year (December 2018 to November 2019). Altogether, 55 undergraduate medical students with age ranging 18-30 years who were smartphone users, enrolled randomly using non probability purposive sampling method. Participants with best corrected distance visual acuity VA $\geq 6 / 9$, near VA $\geq N 8$ with correction also without any accommodative and vergence anomalies, near horizontal phoria not greater than 4 prism dioptre Exo or 2 prism dioptre Eso, subjects with non-invasive tear breakup time (NTBUT) $10 \mathrm{sec}$ or greater were included. But conditions of having any ocular/systemic pathology, history of eye injury/ocular surgery, anisometropia and astigmatism $>1.00 \mathrm{D}$, and self-reported neck/back pain when using a smartphone were excluded.

Informed consent was taken from all subjects before enrolment. Subjects who met the inclusion and exclusion criteria were selected for the experiment, which consisted of four phases: visual function screening, a pre-experiment symptom survey, one hour reading from a smartphone and a post-experiment symptom survey that took approximately $80 \mathrm{~min}$ for each subject to complete.

Monocular visual acuity (VA) of each eye was measured using Snellen's visual acuity chart for distance and near with reduced Snellen's visual acuity chart was used under room illumination. Clinical evaluations after visual acuity measurement were subjective refraction, slit lamp biomicroscopy, NTBUT (Recorded using Topo Tomographer 17042770 Sirius-Italy by asking patient to hold their third blink avoiding first two blinks to evade any nonuniformity of tear film, tear break up was noted. This was repeated twice, and the average tear break up time was measured to rule out dry eye related stress), and posterior segment evaluation. Furthermore, ancillary tests like ocular motility, cover test, near point of convergence (NPC), and amplitude of accommodation were measured with the Royal Air Force Rule at primary gaze. Convergence $<10 \mathrm{~cm}$ was considered normal, whereas the normal value of accommodation was calculated by Hofstetter's formula (Amplitude of accommodation =16-Age/4). Positive fusional vergence (PFV) was measured using a base-out prism bar.

Before starting a smartphone reading, accommodation facility was measured monocularly and binocularly with $\pm 2.00 \mathrm{D}$ accommodative flippers. A survey on normal asthenopic manifestations was directed to subjects before they read a concentrate from a novel on a cell phone, and indications were scored on a scale from zero (not under any condition) to four(extremely). At that point, subjects were approached to peruse a concentrate from a novel "To kill a mockingbird" by Harper Lee on a smartphone for $60 \mathrm{~min}$. The experimental conditions were the same for each participant. A smartphone screen had a dimension of $6.00^{\prime \prime}(15.42 \times 8.38 \times 0.76$ $\mathrm{cm}$ ) and was set to maximum brightness (luminance measured was 100 lux). The black coloured font with a white background of Times New Roman N8 text size was opted and the room illuminance was set to 300 lux. The subjects were not allowed to zoom in or zoom out the text as well as alter the brightness of the screen. Every 20 min the distance between the lateral canthus and a smartphone was measured provided that the reading pattern was not hampered.

Subjects were asked to rate how they felt 'at the moment' on a Likert scale, where $0=$ not at all, $1=$ very slightly, $2=$ slightly, $3=$ moderately, and $4=$ extreme.

All the symptomatic subjects, post- experiment, were educated about healthy and standard usage of digital devices and emphasized to follow the 20:20:20 rule.

\section{STATISTICAL ANALYSIS}

Statistical package for the social Sciences (SPSS version 25) was used for Pre and post -task comparisons with the 
Wilcoxon signed-rank test, and changes during the task were assessed using the Friedman test. The correlation between the subject's viewing distances and the change in their total symptom score was calculated using Spearman correlation test.

\section{RESULTS}

Of the 55 total subjects, $54.5 \%(n=30)$ were male and $45.5 \%(n=25)$ were female. The mean age of participants was 21.25 (SD \pm 2.20 ) years, ranging from 17 to 26 years.

From the 28 possible maximum score, the mean total symptom score was statistically significant, greater post experiment score $(7.07 \pm 2.84)$ than the pre-experiment score $(1.54 \pm 1.60)$ and $p$ value (Table 2$)$ obtained with the Wilcoxon signed-rank test was $p<0.001$. The change in symptom score was not spread evenly throughout the symptoms. Symptoms of tired eyes, uncomfortable eyes, sore eyes, sleepy eyes, headache, and blurred vision increased significantly after 60 min of reading on a smartphone, whereas there was no significant change in the score for symptoms of double vision observed.

The mean viewing distance at the start of reading on a smartphone was $31.17 \pm 3.75 \mathrm{~cm}$ and after one-hour was $30.15 \pm 3.29 \mathrm{~cm}$. When the different phases of time were compared, the mean viewing distance during the first 20 min of the experiment was $30.66 \pm 4.34 \mathrm{~cm}$, during 20 to $40 \mathrm{~min}$ was $30.10 \pm 2.71 \mathrm{~cm}$, and during the last 40 to $60 \mathrm{~min}$ was $29.67 \pm 4.74 \mathrm{~cm}$. On performing Friedman test with post-hoc Wilcoxon signed-rank test, we found a significant reduction in viewing distance (figure: 1) from 1 to $20 \mathrm{~min}$ and after 40 to $60 \mathrm{~min}(\mathrm{p}<0.01)$. The difference in mean viewing distance from 1 to $20 \mathrm{~min}$ and later 20 to $40 \mathrm{~min}$ of experiment was not found to be statistically significant ( $p<0.78$ ). Similarly change in viewing distance during 20 to $40 \mathrm{~min}$ and 40 to 60 min of experiment was also not found to be statistically significant $(p<0.37)$.

Significant variations in accommodative dynamics and tear film break up time were observed, all of which are summarized in Table 3.

The two-tailed Spearman correlation calculated the association between the total symptom score and viewing distance. Subjects who scored high were most likely to have reduced viewing distance $(p=0.26$, $r=-0.301 ; \mathrm{Cl} 95 \%)$. All the subjects who scored high correlated with symptoms of sore eyes $(p=0.04, r=$ -0.38). Contrary to the total symptom score, NTBUT ( $p=$ $0.91, r=-0.014)$ and sleepy eyes $(p=0.06, r=-0.36) \mathrm{did}$ not relate significantly, provided $p<0.05$ was a marker for the level of significance.

Table 1: Eye strain symptom tool ${ }^{9}$

\begin{tabular}{lccccc}
\hline How tired do your eyes feel? & $\mathbf{0}$ & $\mathbf{1}$ & $\mathbf{2}$ & $\mathbf{3}$ & $\mathbf{4}$ \\
\hline How uncomfortable do your eyes feel? & $\times$ & $\times$ & $\times$ & $\times$ & $\times$ \\
\hline How sore do your eyes feel? & $\times$ & $\times$ & $\times$ & $\times$ & $\times$ \\
\hline How sleepy do you feel? & $\times$ & $\times$ & $\times$ & $\times$ & $\times$ \\
\hline Do you have a headache? & $\times$ & $\times$ & $\times$ & $\times$ \\
\hline Do you have any blurred vision? & $\times$ & $\times$ & $\times$ \\
\hline Do you have any double vision? & $\times$ & $\times$ & $\times$ & $\times$ \\
\hline
\end{tabular}

Table 2: Mean pre- and post-experiment eye strain symptom scores

\begin{tabular}{|cccc}
\hline Eye strain symptom & Pre-score & Post-score & p-value \\
\hline Tired eyes & $0.49 \pm 0.69$ & $2.00 \pm 0.74$ & $<0.05$ \\
\hline Uncomfortable eyes & $0.33 \pm 0.54$ & $1.98 \pm 0.73$ & $<0.05$ \\
\hline Sore eyes & $0.24 \pm 0.42$ & $0.93 \pm 0.85$ & $<0.01$ \\
\hline Sleepy feel & $0.40 \pm 0.62$ & $1.11 \pm 0.95$ & $<0.05$ \\
\hline Headache & $0.09 \pm 0.34$ & $0.35 \pm 0.64$ & 0.01 \\
\hline Blurred vision & $0.00 \pm 0.00$ & $0.71 \pm 0.97$ & $<0.01$ \\
\hline Double vision & $0.00 \pm 0.00$ & $0.00 \pm 0.00$ & 1.0 \\
\hline
\end{tabular}


Table 3: Variation in NTBUT and accommodative facility

\begin{tabular}{lccccc}
\hline & \multicolumn{2}{c}{ Pre-experiment } & \multicolumn{2}{c}{ Post-experiment } \\
& Mean & SD & Mean & SD & P-value \\
NTBUT (sec) & 13.51 & 3.68 & 9.71 & 3.97 & $<0.001$ \\
Monocular Accommodative Facility (cycle/min) & 12.77 & 2.66 & 11.1 & 2.11 & $<0.01$ \\
\hline Binocular Accommodative Facility (cycle/min) & 9.17 & 2.4 & 7.03 & 1.99 & $<0.01$ \\
\hline
\end{tabular}

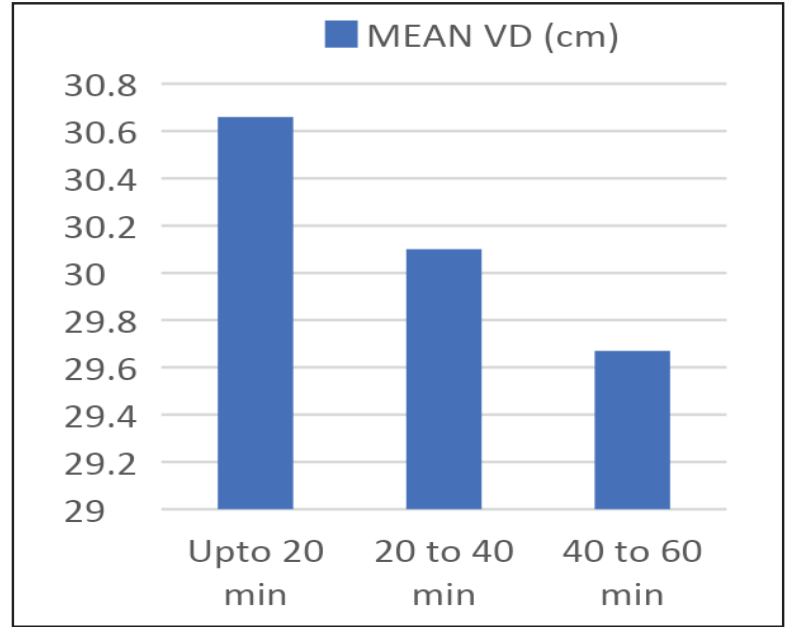

Figure 1: Mean variation of viewing distance (VD)

\section{DISCUSSION}

The usage of a smartly designed visual display unit in the form smartphone, tablet, laptop, etc. is at the peak. It impacts on several ocular as well as postural parameters in prolonged usage. The pre and post total symptom score $1.54 \pm 1.60$ and $7.07 \pm 2.84$, respectively, confirmed eye strain at the end of $60 \mathrm{~min}$, similar to earlier findings $\mathrm{s}^{9,10,11,12}$. We also found that the symptoms of tired, uncomfortable, sore eyes increased after one hour of a smartphone reading. Interestingly, there were symptoms of binocular/accommodative anomalies such as symptoms of headache, blurred vision, and sleepy feel. The exception was the symptom of diplopia, which has been associated with binocular vision as well ${ }^{13}$.

The mean non-invasive tear breakup time before reading on a smartphone was $13.51 \pm 3.68$, and after reading for $60 \mathrm{~min}$ was $9.71 \pm 3.97$. This finding is analogous to Kim et al. ${ }^{12}$ who reported reduced tear breakup time after 60 min of playing a game or watching a movie on a tablet. This may be due to the smartphone position in viewing the reading material. At primary gaze, the increased corneal exposure and continuous staring at one place could be associated with the higher gaze angle and low blink rate resulting in tear evaporation and thereby reduced NTBUT post reading ${ }^{14,15}$.
Viewing distances measured at the time of commencing the experiment was more $(31.17 \pm 3.75 \mathrm{~cm})$, but these distances were not sustained over time and were meaningfully shorter near the termination of the 60-min reading (29.67 \pm 4.74$)$.These results are equivalent with the viewing distance stated in the study by Long et al. ${ }^{9}$ A study by Bababekova et al. ${ }^{16}$, where subjects were instructed to grasp the phone as they usually would and to vary the font size as they wanted to be able to read the text comfortably. Therefore, in this case, the subject's self-perceived posture may be dissimilar from their real posture when captivated in a task. If this is true, then they might have overvalued the viewing distances assumed for handheld smartphones. However, in our study subjects were instructed to hold a smartphone where they usually used to hold it while reading, and to use one of their fingers to scroll and not to alter font size (i.e., font size was kept constant), so they might have adapted to their actual posture. The viewing tasks in these two studies ${ }^{9,16}$ are different (reading in this study, texting and web-browsing in the study of Bababekova et $\mathrm{al}^{16}$, so it is not likely to speculate any added variances from their results.

The total symptom score and viewing distance $(p=0.026$, $r=-3.01$ ) were consistent with the findings of a previous study $^{9}$. The symptom scores that showed the largest increase after the 60- min reading task were tired eyes, uncomfortable eyes, sleepy eyes, sore eyes, and blurred vision. The increase in the sore eyes and sleepy eyes symptom was significantly correlated with a decrease in viewing distance. People adopt closer seeing distances when observing small fonts ${ }^{17}$, apparently to build the precise size of the picture on the retina. In our examination, the angular size of the retinal picture was $22.5^{\prime}$ during the initial $20 \mathrm{~min}$ of the study and $23.4^{\prime}$ during the most recent 20 min of the study. This is marginally larger than the angular size proposals given in the International Standard ISO $2011^{18}$. The perceived difficulty for a visual task is greater when the font is smaller $^{19}$, and subjective comfort ratings are reduced in the presence of visual stress associated with small font $\mathrm{s}^{20}$. Since the size of the font was held constant in this experiment, it is difficult to draw any further conclusions 
about the relationship between font size, perceived difficulty, and visual comfort.

The possibility that the subjects experienced visual stress could be associated with the visual demands of the task and attempted to minimize eye strain symptoms at the end of the 60 -min viewing period by shortening the viewing distance to the smartphone thus, increasing the angular size of the image on the retina, similar to conclusions drawn by other studies ${ }^{21,22}$. On other hand reading closer would further aggravate the accommodation and convergence demand leading further eyestrain.

We found a significant reduction in monocular accommodative facility (MAF) and binocular accommodative facility (BAF) after a smartphone reading for $60 \mathrm{~min}$. The finding of reduced $B A F$ is in agreement with other studies ${ }^{23,24,25}$ in which the authors found a small but statistically significant decrease in BAF after reading from a tablet for $30 \mathrm{~min}$. In contrast, Park $\mathrm{M}$ et al. ${ }^{10}$ did not find a significant effect on monocular and binocular accommodative facilities after $30 \mathrm{~min}$ of viewing a film on a smartphone.

It is likely that the added perceptive mandate from the multifunctionality of these devices may adversely affect accommodation, consequently affecting the ability

\section{REFERENCES}

1. Uchino M, Yokoi N, Uchino Y, Dogru M, Kawashima M, et al. Prevalence of dry eye disease and its risk factors in visual display terminal users: The Osaka study. Am J Ophthalmol. 2013; 156: 759-6. [DOI]

2. Gavali MY, Khismatrao DS, Gavali Y V., Patil KB. Smartphone, the new learning aid amongst medical students. J Clin Diagnostic Res 2017; 11: JC05-JC08. [DOI]

3. Arthur C. The history of smartphones: timeline. Guard. 2012; : 24.

4. Wallace S, Clark M, White J. 'It's on my iPhone': Attitudes to the use of mobile computing devices in medical education, a mixed-methods study. BMJ Open 2012; 2. [DOI]

5. Payne KFB, Wharrad H, Watts K. Smartphone and medical related App use among medical students and junior doctors in the United Kingdom (UK): A regional survey. BMC Med Inform Decis Mak 2012; 12: 121. [DOI]

6. Sayedalamin Z, Alshuaibi A, Almutairi O, Baghaffar M, Jameel T, Baig M. Utilization of smart phones related to make quick focusing changes ${ }^{26}$. Furthermore, the reduced accommodative facility could be due to near work in general and not related specifically to computers or handheld digital devices or vergence could be another possibility to bring an impact.

\section{CONCLUSION}

Asthenopic symptoms are palpable after $60 \mathrm{~min}$ of a smartphone use and are accompanied by reduced viewing distance and monocular and binocular accommodative facilities. The eye strain symptom score increased significantly with a decrease in viewing distance. These findings are important for all users of smartphones, especially those in younger age groups who use a smartphone frequently and for extended durations.

\section{LIMITATIONS}

Automated instruments to measure viewing distance would have added more precise viewing distance. The study design is limited to small sample size and could have been better with inclusion of results according to the specific hours of usage. Subjects were aware that eyestrain was being measured and may have expected to experience symptoms psychologically. Symptoms are subjective and can vary according to the tolerance level of each individual.

medical applications among medical students at King Abdulaziz University, Jeddah: A cross-sectional study. J Infect Public Health 2016; 9: 691-7. [DOI]

7. Karki S, Singh JP, Paudel G, Khatiwada S, Timilsina S. How addicted are newly admitted undergraduate medical students to smartphones?: a cross-sectional study from Chitwan medical college, Nepal. BMC Psychiatry 2020; 20. [DOI]

8. Brian Chou OD. Deconstructing the 20-20-20 Rule for digital eye strain. Optometry Times. 2018 Mar 1;10(3):21-3. [URL]

9. Long J, Cheung R, Duong S, Paynter R, Asper L. Viewing distance and eyestrain symptoms with prolonged viewing of smartphones. Clin Exp Optom 2017; 12453. [DOI]

10. Park M, Ahn YJ, Kim SJ, You J, Park KE, Kim SR. Changes in Accommodative Function of Young Adults in their Twenties following Smartphone Use. J Korean Ophthalmic Opt Soc 2014; 19: 253-60. [DOI]

11. Jaiswal S, Asper L, Long J, Lee A, Harrison K, Golebiowski B. Ocular and visual discomfort associated with smartphones, tablets and computers: 
what we do and do not know. Clin. Exp. Optom. 2019; 102(5): 463-77. [DOI]

12. Kim DJ, Lim C-Y, Gu N, Park CY. Visual Fatigue Induced by Viewing a Tablet Computer with a High-resolution Display. Korean J Ophthalmol 2017; 31: 388-93. [DOI]

13. Schor C, Horner D. Adaptive disorders of accommodation and vergence in binocular dysfunction. Ophthalmic Physiol Opt 1989; 9: 264-8. [DOI]

14. Choi JH, Li Y, Kim SH, Jin R, Kim YH, et al. The influences of smartphone use on the status of the tear film and ocular surface. PLoS One 2018; 13. [DOI]

15. Gowrisankaran S, Sheedy JE. Computer vision syndrome: A review. Work. 2015; 52-2: 303-14. [DOI]

16. Bababekova Y, Rosenfield M, Hue JE, Huang RR. Font size and viewing distance of handheld smart phones. Optom Vis Sci 2011; 88: 795-7. [DOI]

17. J L. The effect of character size on working distance at a computer screen. 2000: 40-5.

18. INTERNATIONAL STANDARD ORGANIZATION. Human-centred design for interactive systems (9241210). In: Ergonomics of humansystem interaction. 2010.

19. Ko P, Mohapatra A, Bailey IL, Sheedy J, Rempel DM. Effect of font size and glare on computer tasks in young and older adults. Optom Vis Sci 2014; 91: 6829. [DOI]
20. Nahar NK, Sheedy JE, Hayes J, Tai YC. Objective measurements of lower-level visual stress. Optom Vis Sci 2007; 84: 620-9. [DOI]

21. Rempel D, Willms K, Anshel J, Jaschinski W, Sheedy J. The effects of visual display distance on eye accommodation, head posture, and vision and neck symptoms. Hum Factors 2007; 45: 830-8. [DOI]

22. Rosenfield M, Ciuffreda KJ. Cognitive demand and transient nearwork-Induced myopia. Optom Vis Sci 1994; 71: 381-5. [DOI]

23. Golebiowski B, Long J, Harrison K, Lee A, ChidiEgboka N, Asper L. Smartphone Use and Effects on Tear Film, Blinking and Binocular Vision. Curr Eye Res 2020; 45: 428-34. [DOI]

24. Kim J, Um JY, Sung HN, Kim SR, Park M. Changes in Accommodative Function after Reading with Paper Book and E-book on Tablet PC. J Korean Ophthalmic Opt Soc 2017; 22: 183-90.: [DOI]

25. Kwon K, Woo JY, Park M, Kim SR. The change of accommodative function by the direction of eye movements during computer game. J Korean Ophthalmic Opt Soc 2012; 17: 177-184.

26. Davies LN, Wolffsohn JS, Gilmartin B. Cognition, ocular accommodation, and cardiovascular function in emmetropes and late-onset myopes. Investig Ophthalmol Vis Sci 2005; 46: 1791-6. [DOI] 